\title{
Neurological control of human sexual behaviour: insights from lesion studies
}

\author{
Amee D Baird, Sarah J Wilson, Peter F Bladin, Michael M Saling, David C Reutens
}

We review the human literature examining the effects of neurological insult on human sexual behaviour. We provide a synthesis of the findings to date, and identify key brain regions associated with specific aspects of human sexual behaviour. These include subcortical and cortical regions, with the mesial temporal lobe and the amygdala in particular being a crucial structure in the mediation of human sexual drive.

See end of article for authors' affiliations

a.r.

Correspondence to:

Dr Amee Baird,

Neuropsychology

Department, Saltpêtrière

Hospital, 47-83 Boulevard

de l'Hôpital, Paris 75013,

France; ameebaird@yahoo.

com.au

Received

19 September 2006

Revised 15 December 2006

Accepted

15 December 2006

Published Online First

22 December 2006
D espite its fundamental role in human life, there has been surprisingly little research into the neurological control of human sexual behaviour. Blumer and Walker ${ }^{1}$ proposed two reasons for this neglect. Firstly, physicians are not routinely trained to explore the sex life of their patients, and secondly, "there has been a stifling trend in research to investigate only what can be measured by objective methods" ${ }^{1}$ Now 30 years later, human studies of the neurological control of sexual behaviour remain scarce. Although we have gained some knowledge from animal studies, ${ }^{2}$ the validity of comparing the sexual behaviour of rodents and humans is questionable. In this review, we focus solely on human research. Recently, there have been a number of functional neuroimaging studies of human sexual arousal. ${ }^{3}$ These studies have typically used visual sexual stimuli that simultaneously activate numerous brain regions associated with a range of sexual functions. Thus although these studies can identify brain areas involved in the mediation of human sexual behaviours, they cannot determine which areas are necessary for particular functions. ${ }^{4}$ Studies of patients with brain lesions are unique in enabling us to examine specific brain-behaviour relationships. Current human lesion research examining the effects of neurological insult on human sexual behaviour comprises case studies, incidental observations and group studies of sexual changes associated with a particular neurological disease, cerebral injury, neurosurgery or direct cortical stimulation. The aim of this review was to synthesise this human literature, and to reflect on the insights that this provides, including identification of brain regions mediating specific aspects of human sexual behaviour. The findings highlight the critical role of the mesial temporal lobes and the amygdalae in the mediation of human sexual drive.

A crucial issue to consider in understanding the neural basis of human sexual behaviour is the distinction between disinhibited sexual behaviour as part of generalised behavioural disinhibition, and hypersexuality, or dramatically increased sexual drive and activity occurring in relative isolation. These two manifestations have been distinguished on the basis of theorised neuroanatomical substrates and effective treatments. Disinhibited sexual behaviour is considered to be a feature of general behavioural disinhibition following paralimbic and neocortical frontotemporal lobe injury, whereas "true hypersexuality" is more commonly associated with limbic and temporal lobe injury (see "Hypersexuality after temporal lobectomy" below). Likewise, hyposexuality may occur following injury to the prefrontal convexity, as part of a general tendency towards apathy and indifference, ${ }^{6}$ or in relative isolation, as in temporal lobe epilepsy. We emphasise the manifestations of hypersexuality and hyposexuality in considering brain-behaviour relationships.

\section{METHODOLOGY}

Articles were ascertained using the databases "PsychInfo" and "PubMed". Keywords included "brain", "sexual behaviour", "sexual function", "hypersexuality" and "hyposexuality", limiting the search to human studies published in English. The literature spans 68 years from 1937 to 2005. The references of articles obtained from the databases were also searched to identify other relevant studies to obtain a comprehensive listing of articles. In this paper, we cite those references that are key to building a coherent picture of the key brain regions mediating human sexual behaviour. Despite these measures, we found a paucity of research addressing this significant clinical issue. Based on the articles reviewed, we have identified particular brain areas in which there have been several reports of lesions causing alterations in sexual behaviour. In addition, we briefly summarise recent functional neuroimaging studies that complement the findings of the lesion research and provide additional evidence in support of the key brain regions identified. The literature has been divided into the broad categories of subcortical and cortical studies. Firstly, we identify neurological insult literature supporting the role of three subcortical regions, specifically the septal region, hypothalamus, and ansa lenticularis and paillidum. This is followed by a review of literature identifying the role of three cortical regions in the meditation of specific aspects of human sexual behaviour, namely the frontal, parietal and temporal lobes, and in particular the

Abbreviations: KBS, Klüver Bucy syndrome; TLE, temporal lobe epilepsy 
amygdalae. Particular brain regions such as the temporal lobes currently have more substantial evidence supporting their role in the mediation of human sexual behaviour than other regions. Thus this review focuses on this integral area. Although other brain regions have fewer observations of associated sexual changes after lesions (for example, the subcortical regions), their inclusion is warranted given the significance of the findings.

\section{SUBCORTICAL REGIONS The septal region}

There have been two observations of sexual responses or altered sexual behaviour after stimulation or damage to the septal region of the limbic system. Heath ${ }^{7}$ conducted direct electrical and chemical stimulation of various areas of the brain in a sample of 54 patients with a range of conditions, including schizophrenia and narcolepsy. He found that a subjective "pleasurable response" and varying degrees of sexual arousal were consistently elicited by electrical stimulation of the septal region in all patients. Heath ${ }^{78}$ developed a self-stimulating device that was attached to intracranial electrodes. This device was based on a technique developed by Olds and Milner ${ }^{9}$ to study the pleasure response in animals. Septal self-stimulation elicited orgasm and a compulsion to masturbate. Chemical stimulation of the septal region elicited similar sexual responses. $^{78}$

Further evidence of the role of the septal nuclei in the mediation of sexual behaviour comes from an incidental finding reported by Gorman and Cummings. ${ }^{10}$ They described two male patients who manifested hypersexuality in the form of a dramatic increase in sexual interest and activity after the insertion of ventriculoperitoneal shunts for the treatment of hydrocephalus. In both patients, CT scans revealed that the tip of the shunt catheter was lodged in the septum. Gorman and Cummings ${ }^{10}$ concluded that the septal injury was responsible for the markedly increased sexual activity and that "the septal nuclei form one locus on an amygdaloid-hypothalamic-septal circuit that mediates sexual behaviour". In particular, the septal region appears to be intrinsically involved in pleasurable response and orgasm.

\section{The hypothalamus}

Isolated hypothalamic lesions have been reported to reduce or abolish sexual drive. ${ }^{11}{ }^{12}$ One 50-year-old male patient in the case series of Miller and colleagues ${ }^{12}$ had hypothalamic damage resulting from an infiltrating glioma of the left midbrain hypothalamic region. He developed erectile and ejaculatory difficulties and a paedophilic sexual preference.

In the 1970s, certain psychosurgical techniques were developed to target sexual behaviour. These were based on experimental work in animals that demonstrated that destruction of the hypothalamic ventromedial nuclei led to the conversion of feline post-amygdalectomy hypersexuality to hyposexuality. ${ }^{13}$ Roeder and colleagues ${ }^{14}$ subsequently developed a stereotaxic method of treating "sexual deviations" in humans. Stereotaxic lesions of the ventral medial hypothalamic nucleus were performed in 10 patients with "sexual deviation" ranging from paedophilic homosexuality to intractable exhibitionism. The results showed that sex drive was diminished or abolished in all cases. ${ }^{14}$

Three case studies of patients with striking changes in sexual behaviour have been reported that were associated with lesions that included the hypothalamus but extended to other brain regions. For example, Poeck and Pilleri ${ }^{15}$ described a female patient who displayed periodic hypersexual and aggressive behaviour after encephalitis of unknown aetiology. Neuropathological examination revealed extensive lesions to limbic structures, including the hypothalamus, thalamic nuclei and the fornix. Ortego and colleagues ${ }^{16}$ described a woman with neuropathologically confirmed multiple sclerosis who developed hypersexuality and multiple paraphilias, including paedophilia, zoophilia and incest over the 2 months prior to her death. She had extensive lesions of limbic structures, including the hypothalamus, basal frontal, septal and temporal regions. Frohman and colleagues ${ }^{17}$ described a male patient with altered sexual behaviour characterised by an obsessive and insatiable desire to touch women's breasts. Neuroimaging showed enhancing lesions on the right side of the hypothalamus and mesencephalon. In summary, these case studies demonstrate that alterations in sexual behaviour and/or orientation can occur in association with various combinations of limbic structure lesions, including the hypothalamus. In particular, the hypothalamus appears to mediate neuroendocrine and autonomic aspects of sexual drive, with focal lesions resulting in a reduction or abolition of sexual drive. In contrast, lesions including but not restricted to the hypothalamus have resulted in increased sexual drive. This apparent paradox may reflect the complexity of this structure and its associations with other brain regions, with the possibility that different nuclei within the hypothalamus serve opposing functions.

Neuroimaging studies of sexual arousal elicited by visual stimuli or during ejaculation have found activation of subcortical regions, including the hypothalamus ${ }^{18-21}$ For example, Ferretti and colleagues ${ }^{21}$ found peak hypothalamic activation at the initial phase of erection and suggested that the hypothalamus may serve to trigger an overt sexual response. These observations support the findings from lesions studies that the hypothalamus is a key brain region in the mediation of human sexual drive.

\section{The ansa lenticularis and pallidum}

Interruption of a bundle of myelinated fibres known as the ansa lenticularis has been found to effect sexual function. These fibres project from the globus pallidus of the basal ganglia to the thalamus. Meyers ${ }^{22}{ }^{23}$ described four patients who exhibited an enduring loss of libido following bilateral surgical lesioning of the ansa lenticularis for the relief of bilateral abnormal movements. Two of these patients presented with parkinsonian tremors and rigidity, and the other two with myoclonic movements. Following surgery all patients experienced alibido, accompanied by impotence in the males. Because of their structural proximity, however, surgical lesioning of the ansa lenticularis can affect the perifornical grey matter, posterior septal region and the dorsomedial nucleus of the hypothalamus. Thus it is not possible to ascertain the exact structure or combination of structures that were responsible for the postoperative alibido in these patients.

Two cases of hypersexuality after pallidotomy for Parkinson's disease have been reported. Mendez and colleagues ${ }^{24}$ described a male patient who manifested hypersexuality immediately following right pallidotomy, which persisted for 1 year and then gradually decreased with a tapering of his antiparkinsonian medications. Roane and colleagues ${ }^{25}$ described a patient who previously underwent a right pallidotomy and developed hypersexuality after surgical implantation of a deep brain stimulator electrode in the left globus pallidus. Overall, these findings suggest that the ansa lenticularis and pallidum play a role in the mediation of sexual drive, and lesions to this area may cause hypersexuality or alibido with impotence in males.

\section{CORTICAL REGIONS}

\section{The frontal lobes}

Disinhibited sexual behaviour has been reported following damage to the frontal lobes, particularly the orbitofrontal region of the limbic system. ${ }^{10}$ As stated in the introduction, some authors consider such behaviour to be a byproduct of 
general behavioural disinhibition occurring after frontal lobe damage. ${ }^{5} 6$

The effect of frontal leucotomy on sexual behaviour has been assessed, ${ }^{26-29}$ with some researchers reporting cases of hypersexuality ${ }^{26}$ and others describing no changes after leucotomy. ${ }^{29}$ Levine and Albert ${ }^{28}$ conducted a thorough exploration of sexual changes after "frontal lobotomy" in 40 patients with various psychiatric diagnoses and found that four patients experienced sexual changes that caused social difficulties, but this was a new feature in only one patient.

Sexual automatisms characterised by writhing, thrusting, rhythmic pelvic movements and handling of the genitalia have been reported in patients with seizures arising from the frontal lobe. ${ }^{30-32}$ Historically, these movements were thought to indicate non-epileptic seizures or hysteria, and the bizarre behaviour that can occur during frontal seizures can still result in the erroneous diagnosis of hysteria. ${ }^{31}$ Spencer and colleagues $^{30}$ observed sexual automatisms in four of 14 patients with frontal lobe lesions. Leutmezer and colleagues ${ }^{32}$ proposed that sexual automatisms should be subdivided into two distinct groups: (1) discrete genital automatisms such as grabbing and fondling the genitals, related to temporal lobe seizure onset and (2) hypermotoric sexual automatisms involving pelvic or truncal thrusting accompanied by genital manipulation, representing a frontal onset. These observations suggest that sexual seizures arising from the frontal lobes activate motor components of sexual behaviour. In other words, it appears that the frontal lobes mediate the motor components of sexual behaviour in addition to the control of sexual response that may be disinhibited after frontal lobe damage in the context of general behavioural disinhibition.

Activation of numerous frontal regions, including the right prefrontal cortex, ${ }^{33} 34$ anterior cingulate cortex and gyrus ${ }^{19} 2034$ and orbitofrontal region ${ }^{19}{ }^{34}$ has been observed during sexual arousal involving masturbation induced orgasm. ${ }^{33}$ Orbitofrontal activation has been interpreted as being related to the representation of pleasant bodily sensations, ${ }^{19}{ }^{34}$ while dorsal anterior cingulate activation has been attributed to the modulation of skeletomotor activities that characterise sexual arousal $^{34}$ and the perceived urge to act. ${ }^{19}$ Ferretti and colleagues $^{21}$ found that during the initial phase of erection anterior cingulate activation peaked and was then maintained while the erection was sustained. They suggested that the activation may reflect the continual correspondence between the affective value of the stimulus and the sexual response. ${ }^{21}$ These studies complement those of lesion studies in identifying a critical role of the frontal lobes in human sexual response.

\section{The parietal lobes}

The parietal cortex, specifically the "paracentral lobule", has been implicated in ictally related sexual phenomena. Sexual seizures arising from the parietal cortex have certain distinguishable features. ${ }^{35} 36$ They may involve heightened sexual arousal or sensations in the genitalia or other erogenous areas. The individual is typically conscious and alert during the episodes and can recognise their sexual nature without necessarily finding them pleasurable or erotic. ${ }^{35}{ }^{36}$ The "ego alien" quality of some parietal sexual seizures has been highlighted by several case studies which noted that focal genital sensations may be described by patients as irritating, painful or frightening. ${ }^{37} 38$

Bancaud and colleagues ${ }^{39}$ described 10 patients with seizures involving sexual manifestations due to involvement of the paracentral lobule and 26 cases of temporal lobe sexual seizures. The authors reported that seizures arising from paracentral lobule lesions involved lateralised parasthesias of the genital areas and occasionally the chest, which were experienced without sexual resonance. In contrast, sexual seizures arising from the temporal lobe involved sexual emotions. This distinction was contradicted by Erickson ${ }^{38}$ who described a female patient with a haemangioma in the right paracentral lobule who experienced episodic "hot spells" and genital sensations, as if she were having sexual intercourse. These symptoms were mislabelled "erotomania" or "nymphomania". ${ }^{1}$ Bates ${ }^{40}$ observed anal retraction on stimulation of the paracentral lobule, while central fissure stimulation elicited sensation on the opposite side of the penis, ${ }^{41}$ and the spreading of paraesthesia from the abdominogenital area to the ipsilateral nipple. ${ }^{42}$ Orgasm and associated autonomic changes may result from the spreading of seizure activity from the parietal or temporal region to the hypothalamus ${ }^{37}$ but the specific neuroanatomical localising value of orgasm is unknown. ${ }^{43}$ In summary, these observations suggest that the medial surface of the parietal lobe is specifically involved in the mediation of genital sensations. ${ }^{35} 36$

\section{The temporal lobes}

The area of the limbic system most frequently implicated in the mediation of human sexual behaviour is the temporal lobes. Accumulating evidence of changes in sexual behaviour following temporal lobe dysfunction has led to the phrase the "libidinous temporal lobe". ${ }^{44}$

\section{Klüver Bucy syndrome}

The integral role of the temporal lobes in the mediation of sexual behaviour was demonstrated by the manifestation of hypersexuality following bilateral temporal lobectomy in rhesus monkeys and subsequently in humans. ${ }^{45}$ Bilateral temporal lobectomy produces a constellation of symptoms that constitute Klüver Bucy syndrome (KBS), including: (1) visual agnosia, an inability to recognise objects by sight, (2) hyperorality, a tendency to examine all objects by mouth, (3) "hypermetamorphosis", an irresistible impulse to react and attend to visual stimuli, (4) emotional changes, particularly an absence of fear or expressions of anger, often termed the "taming effect", (5) changes in dietary habits and (6) hypersexuality.

There have been 27 reports of full blown or partial human KBS. Terzian and Dalle Ore ${ }^{46}$ first reported a case of KBS in a man who underwent bilateral temporal lobectomy for intractable epilepsy. With the exception of hyperorality, all other KBS features were present. Hypersexuality manifested as frequent exhibitionism, homosexual and heterosexual advances toward doctors, and masturbation several times per day. The first full blown case of human KBS was described by Marlowe and colleagues $^{47}$ in a male with herpes encephalitis and associated bilateral temporal lobe damage. Hypersexuality manifested as frequent inappropriate sexual references in conversation and numerous homosexual advances. In their review of human KBS, Lilly and colleagues ${ }^{48}$ noted that alterations of sexual behaviour are common and typically manifest as sexual advances and comments whereas increased copulation or masturbation and changes in sexual orientation are less frequent. Poeck ${ }^{49}$ argued that the chief manifestation of KBS is hyperorality, and proposed that only patients with this feature alone or in combination with other features should be described as manifesting KBS. This notion has implications for the conceptualisation of hypersexuality as a Klüver Bucy feature after temporal resection and suggests that the exclusive manifestation of hypersexuality without other KBS features should not be labelled "KBS".

In almost all cases displaying partial or full blown KBS there has been bitemporal damage. There has been no attempt to further delineate the structures within the temporal lobe that may be responsible for this syndrome, although a number of authors have postulated involvement of the amygdala on the basis of findings from animal studies. Bilateral lesions limited 
to the amygdala in humans, however, do not consistently produce hypersexuality or other features of KBS (see discussion below).

\section{Paraphilias and sexual orientation}

There have been 11 reports of paraphilias, such as fetishism, associated with temporal lobe dysfunction in the literature..$^{50-53}$

Kolarsky and colleagues ${ }^{54}$ examined the relationships between "sexual deviation", age of lesion onset and localisation of lesion (temporal vs extratemporal). The authors defined two diagnostic categories: (1) "sexual deviation", involving a deviation of sexual object (for example, paedophilia). Homosexuality was included in this category, which would now be considered inappropriate, and (2) "sexual disturbances other than deviations", including orgasm in response to stimuli unrelated to the subject's sexual preference, hypersexuality and hyposexuality. ${ }^{54}$ The results showed that "sexual deviation" was associated with early onset lesions (prior to age 3 years). There was an insufficient number of participants with extratemporal lesions of known duration to determine whether the presence of an early lesion per se or an early temporal lesion was the effective variable. Nevertheless, the finding that temporal lesions were significantly more common in patients with "sexual disturbances other than deviations" compared with those without sexual disorder led the authors to claim an association between temporal lobe lesions and "sexual disturbance". They carefully noted, however, that brain lesions are not necessarily present in all cases of sexual disorder. ${ }^{54}$

An association between temporal lobe abnormalities and paedophilia has been reported by Mendez and colleagues. ${ }^{55}$ They described two cases of homosexual paedophilia occurring late in life associated with frontotemporal dementia and bilateral hippocampal sclerosis. Both male patients showed right temporal lobe hypometabolism on positron emission tomography. The authors concluded that bitemporal dysfunction, with a right-sided predominance, results in hypersexuality. They emphasised, however, that there is currently no evidence for a "specific 'paedophilia lesion' in the brain". 55

\section{Temporal lobe epilepsy}

\section{Interictal sexual behaviour}

Alterations in interictal sexual behaviour have been frequently reported in patients with epilepsy, particularly temporal lobe epilepsy (TLE). The most common interictal sexual dysfunction associated with TLE is hyposexuality. ${ }^{546-60}$ Hyposexuality is typically defined as sexual activity less than once per month, and may or may not be accompanied by erectile or orgasmic dysfunction. ${ }^{58}$

Early studies describing a relationship between hyposexuality and TLE have received methodological criticisms. ${ }^{36}$ Control groups and female patients were rarely included, and diagnostic criteria for epilepsy were often poorly defined. Many studies included heterogeneous or biased samples without consideration of comorbid conditions. Nevertheless, the majority of studies have supported an association between TLE and hyposexuality, ${ }^{61}{ }^{62}$ with few exceptions. ${ }^{6364}$ This provides further evidence of the critical role of the temporal lobes in the sexual neural network.

\section{Ictal sexual behaviour}

In general, temporal lobe sexual seizures are thought to involve sexual emotion, which can be contrasted with the isolated genital sensations typically associated with parietal lobe sexual seizures. The manifestation of sexual seizures arising from the temporal lobe is varied. Such seizures can involve erotic feelings that may or may not be accompanied by genital sensations and/ or orgasm. Remillard and colleagues ${ }^{65}$ described 12 female patients with ictal sexual phenomena associated with temporal lobe seizures. The sexual component was the initial event of the complex partial seizure in eight patients. This typically involved an erotic and pleasurable sensation in the genitalia or other erogenous areas, occasionally proceeding to orgasm in four patients. Alternatively, a feeling of sexual arousal or pleasure preceded a brief loss of consciousness. ${ }^{65}$ Warneke ${ }^{66}$ described a male patient with TLE who experienced an orgasmic-like sensation which spread across his face. Sexual automatisms involving sexual statements, simulated intercourse, masturbation and exhibitionism for which the patient is subsequently amnesic have also been reported. ${ }^{67-69}$ These automatisms may or may not be preceded by a sexual aura.

Finally, postictal sexual arousal has been described in patients with TLE. ${ }^{58}$ It typically involves the patient seeking out their "customary sexual outlet" in an appropriate setting, such as a sexually responsive partner. It is recalled by the patient and is not considered part of the immediate postictal phase. It was noted that postictal sexual arousal was only observed among patients who were not markedly hyposexual interictally. ${ }^{158}$

A number of studies have proposed right hemisphere dominance in the mediation of sexual function. An increased incidence of hyposexuality has been reported in patients with right-sided TLE. ${ }^{59} 70$ There is also evidence that ictal sexual manifestations, such as orgasmic auras, typically originate from the right hemisphere. ${ }^{65}$ Toone $^{35}$ has claimed that the proposed laterality effect of seizure related sexual phenomena is supported by the published literature which shows a bias in favour of right-sided pathology over left in a ratio of approximately $2: 1$. Finally, in a recent review of case studies of patients with hyposexuality and hypersexuality and unilateral lesions, Braun and colleagues ${ }^{72}$ found that hyposexuality was associated with left-sided lesions and hypersexuality with right-sided lesions.

\section{Sexual outcome after temporal lobectomy}

Ten studies have examined the effect of epilepsy surgery on sexual behaviour. In general, the majority of patients in each study reported no postoperative change. If a change was described, it was typically an improvement or increase in sexual behaviour. Bladin ${ }^{73}$ found that the majority of patients described improved sexuality, while Blumer and Walker ${ }^{57}$ reported that an equal number of patients described no change or improved sexual function.

Surgical removal of epileptogenic tissue by unilateral temporal lobectomy has been reported to abolish pre-existing sexual paraphilias, ${ }^{50}{ }^{53}$ cause a decline in libido, ${ }^{74}{ }^{75}$ restore normal sexual functioning or occasionally result in hypersexuality. ${ }^{57} 587374$ 76-79 The current literature has focused on temporal lobectomy only, with two exceptions. ${ }^{76} 79$ Christianson and colleagues $^{79}$ targeted both temporal and extratemporal surgery patients (surgery to areas outside of the temporal lobe) but exact details of the final sample were not given, precluding a group comparison. Baird and colleagues $^{76}$ found that postoperative sexual change was significantly more likely in patients undergoing temporal resection (64\%) than extratemporal resection $(25 \%)$. Temporal patients typically reported a sexual increase to a perceived level of "normal" functioning while a small number described an increase or decrease to a level above or below patient perceived normality. ${ }^{76}$ In keeping with the right-sided laterality effect, Baird and colleagues ${ }^{76}$ also found that patients who had undergone right temporal resection were more likely to describe changes in sex drive after surgery than those who had undergone left resection.

\section{Hypersexuality after temporal lobectomy}

Hypersexuality, or a dramatic increase in sexual drive, has been reported in some patients after unilateral temporal 


\begin{tabular}{|c|c|c|c|c|}
\hline $\begin{array}{l}\text { Reference } \\
\text { (author, year) }\end{array}$ & Sample size (n) & $\begin{array}{l}\text { Postoperative sexual } \\
\text { change (operation type) }\end{array}$ & Description of sexual change & Postoperative KBS symptoms \\
\hline Sawa $(1954)^{90}$ & $\begin{array}{l}11 \\
5 \text { schizophrenia, } 5 \text { epilepsy, } 1 \\
\text { "hyperactive idiocy" }\end{array}$ & $\mathrm{n}=2$ (bilateral) & $\begin{array}{l}\text { "Acceleration of sexual } \\
\text { impulses" in the form of } \\
\text { increased sexual innuendo in } \\
\text { conversation }\end{array}$ & $\begin{array}{l}\text { Erroneous recognition of people and } \\
\text { objects. Abnormal oral behaviour, } \\
\text { changes in emotional behaviour } \\
\text { including rage reactions and placidity }\end{array}$ \\
\hline Narabayashi $(1963)^{91}$ & $\begin{array}{l}60 \\
46 \text { epilepsy, } 6 \text { EEG abnormalities } \\
\text { and } 8 \text { severe behavioural } \\
\text { disturbances. } 39 \text { unilateral, } 21 \\
\text { bilateral operations }\end{array}$ & $\mathrm{n}=1$ (not reported) & $\begin{array}{l}\text { "Slight hypersexuality" lasting } \\
\text { only a few days }\end{array}$ & Nil \\
\hline Mark $(1972)^{92}$ & $\begin{array}{l}10 \\
\text { All had intractable TLE with } \\
\text { uncontrollable fear or violence; } 3 \\
\text { unilateral, } 6 \text { bilateral operations, } \\
\text { including } 1 \text { unilateral ATL }\end{array}$ & $\mathrm{n}=1$ (bilateral) & Impotent for $2 y$ after surgery & Hyperphagia lasting 3 months \\
\hline $\operatorname{Kim}(1972)^{93}$ & $\begin{array}{l}63 \\
\text { Patients with either epilepsy or } \\
\text { psychiatric disorders such as } \\
\text { phobia and aggressiveness }\end{array}$ & Not reported & $\begin{array}{l}\text { "Elevation of sexual libido } \\
\text { was generally observed" }\end{array}$ & $\begin{array}{l}\text { Elated mood and increased appetite } \\
\text { were generally observed }\end{array}$ \\
\hline Heimburger $(1978)^{94}$ & $\begin{array}{l}58 \\
14 \text { intractable seizures, } 12 \\
\text { behavioural problems, } 32 \\
\text { both; } 43 \text { unilateral, } \\
15 \text { bilateral operations }\end{array}$ & $n=3$ (not reported) & $\begin{array}{l}\text { Increased sex drive which } \\
\text { lasted from a few days to a } \\
\text { few weeks and subsided }\end{array}$ & Nil \\
\hline Jacobson $(1986)^{95}$ & 1 Chronic self-mutilation & $\begin{array}{l}\mathrm{n}=1 \text { (bilateral } \\
\text { amygdalotomy and } \\
\text { subcaudate tractotomy) }\end{array}$ & $\begin{array}{l}\text { "A complete absence of sexual } \\
\text { contact on the ward or in her } \\
\text { personal life contrasted with } \\
\text { her description of 'sexual } \\
\text { arousal" in my presence" }\end{array}$ & $\begin{array}{l}\text { Disorder of facial recognition, emotional } \\
\text { changes including placidity, } \\
\text { hyperalertness to visual stimuli, motor } \\
\text { stereotypies and oral behaviour }\end{array}$ \\
\hline
\end{tabular}

ATL, anterior temporal lobectomy; TLE, temporal lobe epilepsy.

lobectomy.5877 7880 Blumer $^{58}$ defined hypersexuality as "sexual arousal and response that is clearly abnormal in frequency and intensity for a given individual".

As previously noted, a number of authors have conceptualised hypersexuality after unilateral temporal lobectomy as a feature of KBS. $^{5878} 80{ }^{81}$ For example, Blumer ${ }^{58}$ identified common traits in three patients, including (1) the manifestation of hypersexuality after a "postoperative silent period" of 3-6 weeks, (2) persistent sexual arousal, (3) homosexual behaviour, (4) accompanying dietary changes and (5) loss of anger or "tameness". Blumer ${ }^{58}$ proposed that temporal lobe epileptic discharges result in an excited limbic system, causing episodic hyperaggressiveness and hyposexuality, whereas efficacious surgery results in depression of the limbic system, associated with decreased irritability or tame behaviour and hypersexuality. He noted that the latter state corresponds to KBS. Walker and Blumer ${ }^{81}$ argued that such changes may be due to bitemporal damage. Cogen and colleagues $^{78}$ suggested that hypersexuality after unilateral temporal lobectomy represented a "partial KBS" because of the underlying pathology in the contralateral temporal lobe. No other features of KBS were noted in their patient and the time course of this development was much longer than that observed in nonhuman primates and other human KBS cases which typically manifested within the first year post surgery. Finally, Anson and Kuhlman $^{80}$ proposed that postictal dysfunction of the remaining temporal lobe produced a transient functional bilateral temporal lobectomy in their patient. While these two case studies assumed the presence of bitemporal pathology, one case study raised the possibility that a unilateral temporal lesion could produce complete KBS. ${ }^{82}$ Overall, these sporadic case studies suggest that hypersexuality is a rare but dramatic outcome of unilateral temporal lobectomy.

\section{The amygdalae}

Findings from animal studies have clearly demonstrated that within the temporal lobe it is the amygdala that is the pivotal structure in mediating sexual behaviour. A recent study has directly examined the role of the amygdala in human sexual functioning. Baird and colleagues ${ }^{83}$ compared amygdalar volumes in groups of patients with or without sexual changes following temporal lobe resection for epilepsy and in age matched controls. On average, patients who reported a postoperative sexual increase had a significantly larger amygdalar volume contralateral to the site of their resective surgery than patients with a sexual decrease, no change or controls. There was a significant positive relationship between contralateral amygdalar volume and the maximum degree of sexual change. This suggests that a larger contralateral amygdala may contribute to the expression of increased or improved sexuality after temporal lobe resection. The mechanism underlying this relationship is unclear. One hypothesised mechanism emphasises the role of the amygdala in the processing of emotional stimuli. It has been proposed that the amygdala regulates the attachment of appropriate emotional significance to sensory stimuli and determines reinforcing or discriminative properties of stimuli (see Zald ${ }^{84}$ for a review). A larger amygdala may function better in its role as a processor of emotional stimuli, specifically social/sexual cues, and in the attachment of significance to such stimuli. This would increase the likelihood of sexual response, resulting in a sexual increase. Irrespective of the mechanism, this finding points to an important role of the amygdala in regulating human sexual behaviour, specifically sex drive.

Further evidence for the role of the amygdala in human sexual functioning is derived from the observation that stimulation of the amygdala can elicit human sexual responses. ${ }^{85}$ Gloor $^{85}$ described a "sexual experiential response" during electrical stimulation of the right amygdala in a female patient with epilepsy. On stimulation, the patient described a pleasant feeling in her vulva and inner surface of her thighs as though she were having sexual intercourse. She reported that she experienced the same sexual feeling at the onset of her 
spontaneous seizures. Following stimulation, an after discharge involving the amygdala and other limbic structures of the right temporal lobe was observed with subsequent spread to the temporal neocortex.

Stereotaxic human amygdalotomy, or destruction of part of the amygdala, has been performed for the treatment of severe behavioural disturbances such as intractable aggression or hyperactivity. Methodological differences such as patient selection criteria, length of follow up and lateralisation of lesion make cross study comparisons difficult. The surgical procedures used in humans differ from the "amygdalectomy" typically performed in monkeys. Animal studies have used an anteromedial temporal approach and removed the entire structure by aspiration, invariably resulting in damage to additional temporal lobe structures. Few experimental studies with monkeys have used a stereotaxic approach or aimed to produce amygdalotomies. ${ }^{86}$ Patients who have undergone amygdalotomy allow the postoperative effects of precise amygdala destruction to be examined. In particular, the manifestation of hypersexuality and other symptoms of KBS has been reported in several studies. Table 1 gives a summary of these studies. Other studies have found no evidence of altered sexual behaviour or KBS symptoms after amygdalotomy. ${ }^{87} \mathrm{It}$ is unclear, however, whether researchers specifically questioned patients about sexual changes or relied on self-report or obvious manifestation. Overall, it appears that hypersexuality and other features of KBS are relatively uncommon after selective amygdalotomy in humans. When sexual changes occur, they are typically more subtle than those observed in animals, possibly reflecting the greater complexity of human sexual behaviour.

Further evidence for the integral role of the amygdalae in mediating human sexual drive is gained from functional neuroimaging studies which have demonstrated amygdalar activation in response to sexual stimuli. ${ }^{18} 202134$ Interestingly, two positron emission tomography studies of sexual arousal and ejaculation found deactivation of temporal areas, including the amygdale. ${ }^{19} 89$ This deactivation was interpreted as an alleviated inhibition allowing for the development of sexual arousal. ${ }^{19}$ Hamann and colleagues ${ }^{18}$ proposed a differential role for the amygdala in male appetitive versus consummatory sexual responses, as highlighted in previous animal studies. Specifically, consummatory sexual behaviour (erection and orgasm) corresponds with decreased amygdala activity whereas appetitive sexual behaviour (viewing of sexual stimuli) is associated with amygdala activation. Further research is required to examine this proposal.

\section{BRAIN REGIONS MEDIATING HUMAN SEXUAL BEHAVIOUR}

Table 2 shows the key brain regions mediating human sexual behaviour based on a review of the human literature examining the effect of neurological insult on sexual behaviour, and recent functional neuroimaging findings that complement this research. Six main regions, and their associated sexual functions, are identified, including three subcortical and three cortical regions. The subcortical regions comprise: (1) the septal region, involved in the mediation of pleasurable response and orgasm, (2) the hypothalamus, mediating neuroendocrine and autonomic aspects of sexual drive with possible involvement in sexual orientation and (3) the ansa lenticularis and pallidus, implicated in the mediation of sexual drive. The cortical regions comprise: (4) the frontal lobes, mediating the motor components of sexual behaviour and the control of sexual response, (5) the parietal lobes, specifically the paracentral lobule, involved in genital sensation and (6) the temporal lobes, in particular the amygdalae, implicated in sexual orientation, sexual drive and disorders of sexual function (eg, paraphilias).

The neurobiology of sexual behaviour can be conceptualised in terms of the various facets of the human sexual response cycle defined by Kaplan ${ }^{96}$ who proposed a triphasic model: (1) sexual desire, (2) excitement and (3) orgasm. Kaplan ${ }^{96}$ argued that the three phases are interconnected but governed by separate neurophysiological systems. Associations between the key brain regions we have identified and phases of the sexual response cycle can be made. The current evidence from lesion

Table 2 Key brain regions mediating human sexual behaviour

\begin{tabular}{|c|c|c|c|c|c|}
\hline Key brain regions & Sexual function & $\begin{array}{l}\text { Psychosurgery/ } \\
\text { neurosurgery/ } \\
\text { stimulation }\end{array}$ & Seizure related & Other: case studies & Neuroimaging \\
\hline \multicolumn{6}{|l|}{ Subcortical } \\
\hline Septal region & $\begin{array}{l}\text { Pleasurable response } \\
\text { and orgasm }\end{array}$ & $\begin{array}{l}\text { Heath }(1964,1972)^{78} \\
\text { Gorman }(1992)^{10}\end{array}$ & & & \\
\hline Hypothalamus & $\begin{array}{l}\text { Neuroendocrine and } \\
\text { autonomic aspects of } \\
\text { sexual drive, sexual } \\
\text { orientation }\end{array}$ & Roeder $(1972)^{14}$ & & $\begin{array}{l}\text { Poeck }(1965)^{15} \\
\text { Ortego }(1993)^{16}\end{array}$ & $\begin{array}{l}\text { Hamann }(2004){ }_{1}^{18} \\
\text { Redoute }(2000),{ }_{19}^{19} \\
\text { Beauregard }(2001),{ }^{20} \\
\text { Ferretti }(2005)^{21}\end{array}$ \\
\hline Ansa lenticularis and pallidus & $\begin{array}{l}\text { Sexual drive alibido/ } \\
\text { hypersexuality }\end{array}$ & $\begin{array}{l}\text { Meyers (1961, } \\
1962){ }^{22} 23 \\
\text { Mendez }(2004)^{24}\end{array}$ & & & \\
\hline \multicolumn{6}{|l|}{ Cortical } \\
\hline Frontal lobes & $\begin{array}{l}\text { Motor components of } \\
\text { sexual behaviour, control } \\
\text { of sexual response } \\
\text { (disinhibition) }\end{array}$ & $\begin{array}{l}\text { Freeman }(1943)_{1}{ }^{27} \\
\text { Levine }(1951)^{28}\end{array}$ & $\begin{array}{l}\text { Spencer }(1983),{ }^{30} \\
\text { Williamson }(1985),{ }^{31} \\
\text { Leutmetzer }(1999)^{32}\end{array}$ & & $\begin{array}{l}\text { Hamann }(2004),{ }_{19}^{18} \\
\text { Redoute }(2000),{ }_{19}^{19} \\
\text { Ferretti }(2005),{ }^{21} \\
\text { Tiihonen }(1994),{ }^{33} \\
\text { Karama }(2002)^{34}\end{array}$ \\
\hline $\begin{array}{l}\text { Parietal lobes: paracentral } \\
\text { lobule }\end{array}$ & Genital sensation & $\begin{array}{l}\text { Bates }(1953)^{40}{ }^{40} \\
\text { Penfield }(1950)^{42}\end{array}$ & $\begin{array}{l}\text { Toone }(1991,1995),,^{3536} \\
\text { Ruff }(1980),{ }^{37} \\
\text { Erickson }(1945))^{38} \\
\text { Bancaud }(1970)^{39}\end{array}$ & & \\
\hline Temporal lobes: amygdala & $\begin{array}{l}\text { Sexual orientation, sexual } \\
\text { disorders (eg, paraphilias), } \\
\text { sexual drive (hypo/ } \\
\text { hypersexuality, impotence) }\end{array}$ & $\begin{array}{l}\text { Gloor }(1986))^{85} \\
\text { Kim }(1972)^{93},\end{array}$ & $\begin{array}{l}\text { Bancaud }(1970){ }^{39} \\
\text { Mitchell }(1954){ }^{50} \\
\text { Gastaut }(1954){ }^{56} \\
\text { Blumer }(1967),{ }^{57} \\
\text { Remillard }(1983){ }^{65} \\
\text { Baird }(2003),{ }^{, 6}\end{array}$ & $\begin{array}{l}\text { Terzian }(1955),{ }^{46} \\
\text { Marlowe }(1975){ }^{47} \\
\text { Lilly }(1983),{ }^{48} \\
\text { Kolarsky }(1967),{ }^{54} \\
\text { Mendez }(2000)^{55}\end{array}$ & $\begin{array}{l}\text { Hamann }(2004))_{1}^{18} \\
\text { Redoute }(2000),{ }_{19} \\
\text { Beauregard }(2001),{ }^{20} \\
\text { Ferretti }(2005),{ }_{1}^{21} \\
\text { Baird }(2004){ }^{83} \\
\text { Holstege }(2003)^{89}\end{array}$ \\
\hline
\end{tabular}


studies to date suggests that the initial phase, sexual desire, is mediated by subcortical structures, specifically the hypothalamus, ansa lenticularis and pallidum. The temporal lobes, specifically the amygdalae, also play a significant role in this initial phase. Sexual excitement (phase 2) is mediated by cortical structures, namely the parietal and frontal lobes, controlling genital sensation and the motor aspects of sexual response, respectively, sustaining sexual activity until progression to orgasm (phase 3 ) for which the septal region has been implicated. Rather than a linear progression between phases and underlying mediating neural structures, it is likely that there is an interconnected neural network where various brain regions and associated phases of sexual response are simultaneously activated, producing the physical and psychological manifestations of human sexuality. Further research is required to delineate this complex network.

\section{LIMITATIONS}

Our identification of the key brain regions involved in the mediation of human sexual behaviour is primarily based on the findings of single case studies, and the occasional incidental observation. Case studies have a number of methodological constraints, including the validity of extrapolating from single patient observations. Nevertheless, a case study often provides the first insight into a specific phenomenon, and can stimulate further research. A limitation in the study of the behavioural effects of human brain lesions is that with the exception of neurosurgical cases and brain injuries, we must rely on naturally occurring neurological events. Therefore, observations at the single case level often constitute a unique opportunity to investigate a phenomenon, and consequently provide an important step in contributing to our understanding of human brain-behaviour relationships.

There have been very few group studies of changes in sexual behaviour associated with focal cerebral injury or neurosurgery. With the exception of one small scale study of sexual outcome after frontal lobotomy, ${ }^{28}$ these studies are entirely limited to temporal lobe conditions, primarily involving patients with temporal lobe epilepsy or patients with psychiatric conditions who have undergone amygdalotomy. Thus there is substantial evidence supporting the significant role of the temporal lobes in mediating human sexual behaviour. In contrast, support for the role of other cortical and subcortical regions relies heavily on case studies. In particular, there have been no group studies of sexual outcome after subcortical lesions. The scarce number of studies to date indicates that large scale and systematic research into the neurological control of human sexual behaviour is long overdue.

There is a paucity of neuroimaging research examining the neural correlates of human sexual behaviour. With the exception of the recent study by Ferretti and colleagues, ${ }^{21}$ all studies to date have used visual sexual stimuli that simultaneously activate various regions of the sexual neural network and correspondingly numerous phases of the sexual response cycle. Future neuroimaging research needs to clarify the relationship between specific components of the human sexual response cycle and corresponding neural substrates.

\section{CONCLUSION}

We have provided the first synthesis of the literature to date examining the effects of neurological insult on human sexual behaviour, and complementary functional neuroimaging findings. Our understanding of this issue is limited and primarily based on case and small scaled studies. There is, however, considerable convergence among the available research that has enabled the identification of six key brain regions, each mediating specific aspects of human sexual behaviour.
Accumulating evidence suggests that the temporal lobes are a critical region in the mediation of human sexual behaviour, with the amygdalae playing an integral role in regulating human sexual drive. This review highlights the need for further examination of the neural correlates of this fundamental and universal aspect of human life. It is hoped that this review will stimulate further research, particularly into the key brain regions we have identified to date.

\section{Authors' affiliations \\ Amee D Baird, Sarah J Wilson, Michael M Saling, School of Behavioural} Science, Department of Psychology, University of Melbourne, Australia Peter F Bladin, Comprehensive Epilepsy Program, Epilepsy Research Centre, Austin Health, Melbourne, Australia

David C Reutens, Department of Neurology, Monash Medical Centre, Melbourne, Australia

Competing interests: None.

\section{REFERENCES}

1 Blumer D, Walker AE. The neural basis of sexual behaviour. In: Benson DF, Blumer D, eds. Psychiatric aspects of neurological disease. New York: Grune \& Stratton, 1975: 199-217.

2 Meisel RL, Sachs BD. The physiology of male sexual behaviour. In: Knobil E, Neill JD, Greenwald GS, et al, eds. The physiology of reproduction, vol 2. New York: Raven Press, 1994:3-105.

3 Karama S, Lecours AR, Leroux JM, et al. Areas of brain activation in males and females during viewing of erotic film excerpts. Hum Brain Mapp 2002;16:1-13.

4 Price CJ, Friston KJ. Degeneracy and cognitive anatomy. Trends Cogn Sci 2002:6:416-21

5 Zasler ND, Horn $\amalg$. Rehabilitative management of sexual dysfunction. J Head Trauma Rehabil 1990;5:14-24.

6 Blumer D, Benson DF. Personality changes with frontal and temporal lobe lesions. In: Benson DF, Blumer D, eds. Psychiatric aspects of neurological disease. New York: Grune \& Stratton, 1972:151-69.

7 Heath RG. Pleasure response of human subjects to direct stimulation of the brain: Physiologic and psychodynamic considerations. In: Heath RG, ed. The role of pleasure in behavior. New York: Harper \& Row, 1964:219-43.

8 Heath RG. Pleasure and brain activity in man. J Nerv Ment Dis 1972;154:3-18.

9 Olds J, Milner P. Positive reinforcement produced by electrical stimulation of septal area and other regions of rat brain. J Comp Physiol Psychol 1954;47:419-27.

10 Gorman DG, Cummings JL. Hypersexuality following septal injury. Arch Neurol 1992;49:308-10.

11 Baver HG. Endocrine and metabolic conditions related to pathology in the hypothalamus: a review. J Nerv Ment Dis 1959;128:323-37.

12 Miller BL, Cummings JL, Mclntyre H, et al. Hypersexuality or altered sexual preference following brain injury. J Neurol Neurosurg Psychiatry 1986;49:867-73.

13 Schreiner L, Kling A. Behavioral changes following rhinencephalic injury in cat. J Neurophysiol 1953;16:643-59.

14 Roeder F, Orthner H, Müller D. The stereotaxic treatment of pedophilic homosexuality and other sexual deviations. In: Hitchcock E, Laitinen L, Vaernet K, eds. Psychosurgery. Springfield: Charles C Thomas, 1972:87-111.

15 Poeck K, Pilleri G. Release of hypersexual behaviour due to lesion in the limbic system. Acta Neurol Scand 1965;41:233-44.

16 Ortego N, Miller BM, Itabashi H, et al. Altered sexual behavior with multiple sclerosis: A case report. Neuropsychiatry Neuropsychol Behav Neurol 1993;6:260-64.

17 Frohman EM, Frohman TC, Moreault AM. Acquired sexual paraphilia in patients with multiple sclerosis. Arch Neurol 2002;59:1006-10.

18 Hamann S, Herman RA, Nolan CL, et al. Men and women differ in amygdala response to visual sexual stimuli. Nat Neurosci 2004;7:411-16.

19 Redoute J, Stolero S, Gregoire MC, et al. Brain processing of visual sexual stimuli in human males. Hum Brain Mapp 2000;1 1:162-77.

20 Beauregard $M$, Levésque J, Bourgouin P. Neural correlates of conscious selfregulation of emotion. J Neurosci 2001;21:1-6.

21 Ferretti A, Massimo C, Del Gratta C, et al. Dynamics of male sexual arousal: distinct components of brain activation revealed by FMRI. Neuroimage 2005;26:1086-96.

22 Meyers R. Evidence of a locus of the neural mechanisms for libido and penile potency in the septo-fornico-hypothalamic region of the human brain. Trans Am Neurol Ass 1961;86:81-5.

23 Meyers R. Three cases of myoclonus alleviated by bilateral ansotomy, with a note on postoperative alibido and impotence. J Neurosurg 1962;19:71-81.

24 Mendez MF, O'Connor SM, Lim GT. Hypersexuality after right pallidotomy for Parkinson's disease. J Neuropsychiatry Clin Neurosci 2004; 16:37-40.

25 Roane DM, Yu M, Feinberg TE, et al. Hypersexuality after pallidal surgery in Parkinsons disease. Neuropsychiatry Neuropsychology Behav Neurol 2002; 15:247-51

26 McKenzie KG, Procter LD. Bilateral frontal lobe leubotomy in the treatment of mental disease. Can Med J 1946;55:433. 
27 Freeman W, Watts JW. Prefrontal lobotomy. Am J Psychiatry 1943;99:798-806.

28 Levine J, Albert H. Sexual behavior after lobotomy. J Nerv Ment Dis $1951 ; 113: 323-41$

29 Hutton EL. Personality changes after lobotomy. J Ment Sci 1947;93:31.

30 Spencer SS, Spencer DD, Williamson PD, et al. Sexual automatisms in complex partial seizures. Neurology 1983;33:527-33.

31 Williamson PD, Spencer DD, Spencer SS, et al. Complex partial seizures of frontal origin. Ann Neurol 1985;18:497-504.

32 Leutmezer F, Serles W, Bacher J, et al. Genital automatisms in complex partial seizures. Neurology 1999;52:1188-91.

33 Tiihonen J, Kuikka J, Kupila J, et al. Increase in cerebral blood flow of right prefrontal cortex in man during orgasm. Neurosci Lett 1994;170:241-3.

34 Karama S, Lecours AR, Leroux AR, et al. Areas of brain activation in males and females during viewing of erotic film excerpts. Hum Brain Mapp 2002;16:1-13.

35 Toone B. Sex, sexual seizures and the female with epilepsy. In: Trimble MR, eds. Women and epilepsy. West Sussex: John Wiley \& Sons, 1991:201-6.

36 Toone B. Epilepsy and sexual life. In: Hopkins A, Shorvon S, Cascino G, eds. Epilepsy, 2nd ed. London: Chapman \& Hall, 1995:557-64.

37 Ruff RL. Orgasmic epilepsy. Neurology 1980;30:1252.

38 Erickson TC. Erotomania (nymphomania) as an expression of cortical epileptiform discharge. Arch Neurol Psychiatry 1945;53:226-31.

39 Bancaud J, Favel P, Bonis A, et al. Manifestations sexuelles paroxystiques ef epilepsie temporale. Rev Neurol 1970;123:217-30.

40 Bates JAE. Stimulation of the medial surface of the human cerebral hemisphere after hemispherectomy. Brain 1953;76:405-47.

41 Penfield W, Boldrey E. Somatic motor and sensory representation in the cerebral cortex of man as studied by electrical stimulation. Brain 1937;60:389-443.

42 Penfield W, Rasmussen TB. The cerebral cortex of man. New York: Macmillan and Co, 1950:248.

43 Hoenig J, Hamilton CM. Epilepsy and sexual orgasm. Acta Psychiatr Neurol Scand 1960;35:448-57.

44 Walker AE. The libidinous temporal lobe. Arch Suisses Neurol Neurochirurg Psychiatrie 1972:111:473-84.

45 Klüver H, Bucy PC. Preliminary analysis of functions of the temporal lobes in monkeys. Arch Neurol Psychiatry 1939;42:979-1000.

46 Terzian H, Dalle Ore G. Syndrome of Klüver and Bucy reproduced in man by bilateral removal of the temporal lobes. Neurology 1955;5:373-80.

47 Marlowe WB, Mancall EL, Thomas JL. Complete Klüver Bucy syndrome in man. Cortex 1975;11:53-9.

48 Lilly R, Cummings JL, Benson F, et al. The human Klüver-Bucy Syndrome. Neurology 1983;33:1141-5.

49 Poeck K. Pathophysiology of emotional disorders associated with brain damage. In: Vinken PJ, Bruyn GW, eds. Handbook of clinical neurology, disorders of higher nervous activity, vol 3. Amsterdam: New-Holland Publishing Company, 1969:343-67.

50 Mitchell W, Falconer MA, Hill D. Epilepsy with fetishism relieved by temporal lobectomy. Lancet 1954;267:626-30.

51 Davies BM, Morgenstern FS. A case of cysticercosis, temporal lobe epilepsy and transvestism. J Neurol Neurosurg Psychiatry 1960;23:247-9.

52 Epstein AW. Relationship of fetishism and transvestism to brain and particularly temporal lobe dysfunction. J Nerv Ment Dis 1961;133:247-53.

53 Hunter R, Logue V, McMenemy WH. Temporal lobe epilepsy supervening on longstanding transvestism and fetishism. Epilepsia 1963;4:60-5.

54 Kolarsky A, Freund K, Machek J, et al. Male sexual deviation: Association with early temporal lobe damage. Arch Gen Psychiatry 1967;17:735-43.

55 Mendez MF, Chow T, Ringman J, et al. Pedophilia and temporal lobe disturbances. J Neuropsychiatry Clin Neurosci 2000;12:71-6.

56 Gastaut H, Collomb H. Etude du comportment sexuel chez les epileptiques psychomoteurs. Ann Med Psychol 1954;11:657-96.

57 Blumer D, Walker AE. Sexual behaviour in temporal lobe epilepsy: A study of the effects of temporal lobectomy on sexual behaviour. Arch Neurol 1967; 16:37-43.

58 Blumer D. Hypersexual episodes in temporal lobe epilepsy. Am J Psychiatry 1970;126:1099-106

59 Herzog AG, Seibel MM, Schomer DL, et al. Reproductive endocrine disorders in women with partial seizures of temporal lobe origin. Arch Neurol 1986:43:341-6.

60 Herzog AG, Seibel MM, Schomer DL, et al. Reproductive endocrine disorders in men with partial seizures of temporal lobe origin. Arch Neurol 1986;43:347-50

61 Shukla GD, Srivastava ON, Katiyar BC. Sexual disturbances in temporal lobe epilepsy: A controlled study. Br J Psychiatry 1979;134:288-92.

62 Damerdash A, Shaalan M, Midani A, et al. Sexual behavior of a sample of females with epilepsy. Epilepsia 1991;32:82-5.

63 Fenwick PBC, Toone BK, Wheeler MJ, et al. Sexual behaviour in a centre for epilepsy. Acta Neurol Scand 1985;71:428-35.

64 Murialdo G, Galimberti CA, Fonzi S, et al. Sex hormone and pituitary function in male epileptic patients with altered and normal sexuality. Epilepsia 1995:36:360-5.
65 Remillard GM, Andermann F, Franco Testa G, et al. Sexual ictal manifestations predominate in women with temporal lobe epilepsy: A finding suggesting sexual dimorphism in the human brain. Neurology 1983;33:323-30.

66 Warneke LB. A case of temporal lobe epilepsy with an orgasmic component. Can Psychiatr Assoc J 1976:21:319-24.

67 Currier RD, Little SC, Suess JF, et al. Sexual seizures. Arch Neurol $1971 ; 25: 260-4$

68 Freemon FR, Nevis AH. Temporal lobe sexual seizures. Neurology 1969:19:87-90.

69 Hooshmand H, Brawley BW. Temporal lobe seizures and exhibitionism. Neurology 1969;19:1119-24.

70 Bear DM, Fedio P. Quantitative analysis of interictal behaviour in temporal lobe epilepsy. Arch Neurol 1977;34:454-67.

71 Daniele A, Azzoni A, Bizzi A, et al. Sexual behavior and hemispheric laterality of the focus in patients with temporal lobe epilepsy. Biol Psychiatry 1997;42:617-24

72 Braun CM, Dumont M, Duval J, et al. Opposed left and right brain hemisphere contributions to sexual drive: a multiple lesion case analysis. Behav Neurol 2003; 14:55-61.

73 Bladin PF. Psychosocial difficulties and outcome after temporal lobectomy. Epilepsia 1992;33:898-907.

74 Falconer MA, Hill D, Meyer A, et al. Treatment of temporal lobe epilepsy by temporal lobectomy: A survey of findings and results. Lancet 1955;268:827-35.

75 Jensen I, Larsen JK. Mental aspects of temporal lobe epilepsy: Follow up of 74 patients after resection of a temporal lobe. J Neurol Neurosurg Psychiatry 1979:42:256-65

76 Baird AD, Wilson SJ, Bladin PB, et al. Sexual outcome after epilepsy surgery. Epilepsy Behav 2003;4:268-78

77 Baird AD, Wilson SJ, Bladin PB, et al. Hypersexuality after temporal lobe resection. Epilepsy Behav 2002;3:173-81.

78 Cogen PH, Antunes JL, Correll JW. Reproductive function in temporal lobe epilepsy: The effect of temporal lobectomy. Surg Neurol 1979;12:243-6.

79 Christianson SA, Silfvenius H, Saisa J, et al. Life satisfaction and sexuality in patients operated for epilepsy. Acta Neurol Scand 1995;92:1-6.

80 Anson JA, Kuhlman DT. Post ictal Klüver Bucy syndrome after temporal lobectomy. J Neurol Neurosurg Psychiatry 1993;56:31 1-13.

81 Walker AE, Blumer D. Localization of sex in the brain. In: Zülch KJ, Creutzfeldt O, Galbraith GC, eds. Cerebral localization. Berlin: Springer-Verlag, 1975:184-99.

82 Ghika-Schmid F, Assal G, De Tribolet N, et al. Klüver Bucy syndrome after left anterior temporal resection. Neuropsychologia 1995;33:101-13.

83 Baird AD, Wilson SJ, Bladin PB, et al. The amygdala and sexual drive: Insights from temporal lobe resection in intractable epilepsy. Ann Neurol 2004;55:87-96.

84 Zald DH. The human amygdala and the emotional evaluation of sensory stimuli. Brain Res Brain Res Rev 2003;41:88-123.

85 Gloor P. Role of the human limbic system in perception, memory, and affect: Lessons from temporal lobe epilepsy. In: Doane BK, Livingston $\mathrm{KE}$, eds. The limbic system: functional organization and clinical disorders. New York: Raven Press, 1986:159-69

86 Aggleton JP, Passingham RE. Syndrome produced by lesions of the amygdala in monkeys (macaca mulatta). J Comp Physiol Psychol 1981;95:961-77.

87 Vaernet K, Madsen A. Stereotaxic amygdalotomy and basofrontal tractotomy in psychotics with aggressive behaviour. J Neurol Neurosurg Psychiatry 1970:33:858-63.

88 Kiloh LG, Gye RS, Rushworth RG, et al. Sterotactic amydaloidotomy for aggressive behaviour. J Neurol Neurosurg Psychiatry 1974;37:437-44

89 Holstege G, et al. Brain activation during human male ejaculation. J Neurosci 2003;23:9185-93.

90 Sawa M, Ueki Y, Arita M, et al. Preliminary report on the amygdaloidectomy on the psychotic patients, with interpretation of oral-emotional manifestation of schizophrenics. Folia Psychiatr Neurol Jpn 1954;7:309-29.

91 Narabayashi H, Nagao T, Saito Y, et al. Stereotaxic amygdalotomy for behaviour disorders. Arch Neurol 1963:9:11-26.

92 Mark VH, Sweet WH, Ervin FR. The effect of amygdalotomy on violent behavior in patients with temporal lobe epilepsy. In: Hitchcock E, Latinen L, Vaernet K, eds. Psychosurgery. Springfield: Charles C Thomas, 1972:39-155.

93 Kim YK, Umbach W. Combined stereotactic lesions for treatment of behaviour disorders and severe pain. In: Laitinen LV, Livingston KE, eds. Surgical approaches in psychiatry. Lancaster: Medical and Technical Publishing, 1972:182-8.

94 Heimburger RF, Small IF, Small JG, et al. Stereotactic amygdalotomy for convulsive and behavioural disorders. App Neurophysiol 1978;41:43-51

95 Jacobson R. Disorders of facial recognition, social behaviour and affect after combined bilateral amygdalotomy and subcaudate tractotomy-a clinical and experimental study. Psychol Med 1986;16:439-50.

96 Kaplan HS. Disorders of sexual desire. New York: Simon \& Schuster, 1979. 